\title{
Familial prevalence of inflammatory bowel disease in northern Alberta
}

\author{
BR PInchbeck, PhD, J KirdeIKIS, BSc, ABR ThOMSON, MD, PHD, FRCPC
}

\begin{abstract}
Previous studies have reported a high prevalence of inflammatory bowel disease among the relatives, and especially siblings, of patients with Crohn's disease or ulcerative colitis. This high familial prevalence of Crohn's disease and ulcerative colitis suggests that genetic factors could play a role in the development of these disorders. The present study attempted to assess the relative risk for relatives of Crohn's disease and ulcerative colitis patients based on data provided by 1015 questionnaires completed by patients in northern Alberta. A $\chi^{2} 2 \times 2$ test among relatives was performed on the diseased versus normal data for each diagnosis to determine if significant differences existed. The prevalence for mothers and sisters was the highest of the relative groups for Crohn's disease ( 6430 of $10^{5}$ and 4670 of $10^{5}$, respectively). Female relatives tended to have twice the prevalence of their male counterparts. There were differences between mother, daughter and sister prevalence rates for Crohn's disease. These results support the hypothesis that a genetic predisposition in families combined with possible environmental and lifestyle influences determine the relative risk of developing Crohn's disease and ulcerative colitis. Can J Gastroenterol $1990 ; 4(5): 184-186$
\end{abstract}

Key Words: Crohn's disease, Epidemiology, Familial prevalence, Gender, Location of residence, Ulcerative colitis

\section{Prévalence familiale des entéropathies inflammatoires chroniques dans le nord de l'Alberta}

RESUME: Des études antérieures rapportent la prévalence élevée des entéropathies inflammatoires parmi les proches des malades souffrant de maladie de Crohn ou de colite ulcéreuse - frères et soeurs surtout. Cette prévalence familiale semble indiquer que certains facteurs génétiques jouent peut-être un rôle dans l'évolution de ces affections. S'appuyant sur les données tirées de 1015 questionnaires distribués dans le nord de l'Alberta et remplis par des patients atteints de maladie de Crohn ou de colite ulcéreuse, la présente étude tente

Nutrition and Metabolism Research Group, Department of Medicine, University of Alberta, Edmonton, Alberta

Correspondence and reprints: Dr ABR Thomson, 519 Robert Newton Research Building,

University of Alberta, Edmonton, Alberta T6G 2C2

Received for publication January 3, 1989. Accepted May 15, 1990
$\mathrm{T}$ HE UNCERTAIN ETIOLOGY OF IN. flammatory bowel disease has prompted interest in the possible influence of genetic factors on the prevalence of Crohn's disease and chronic idiopathic ulcerative colitis. Epidemiological studies of families with members afflicted with these disorders are useful in assessing the relative risk of people with familial connections, and in the identification of trends which might point to possible genetic involvement in the development of Crohn's disease and ulcerative colitis (1-7).

The purpose of this study was to determine the number of cases of Crohn's disease and ulcerative colitis in which there was a familial connection in northern Alberta. The results indicate that the prevalence of Crohn's disease is markedly increased in the mothers, sisters and daughters of female patients with Crohn's disease compared to their male counterparts. This suggests that genetic as well as environmental factors may be important in the development of Crohn's disease and ulcerative colitis.

\section{PATIENTS AND METHODS}

The area included in this study was the northern half of the province of Alberta, which had a population of $1,295,360$ people in 1981. Ap- 
d'évaluer le risque relatif auquel est exposée la parenté des patients interrogés. Pour chaque diagnostic, un test $\chi^{2}$ a été effectué parmi les familles et sur les données malades/saines, afin de déceler toute différence significative. La prévalence pour les mères et les soeurs étaient la plus élevée de tous les groupes de parents pour le maladie de Crohn $\left(6430 / 10^{5}\right.$ et $4670 / 10^{5}$, respectivement). Les femmes semblaient deux fois plus exposées que les hommes du groupe correspondant. Il existait certaines différences entre les taux de prévalence mère-fille et soeur dans le cas de la maladie de Crohn. Ces résultats appuient l'hypothèse selon laquelle il existe une prédisposition génétique familiale, peut-être combinée à certains facteurs relatifs au milieu et au mode de vie, permettant de déterminer le risque relatif de contracter une maladie de Crohn ou une colite ulcéreuse.

\section{TABLE 1}

Number of diseased relatives, number of relatives in the sample and percentage of diseased relatives with Crohn's disease and ulcerative colitis for index patients

\begin{tabular}{lcccccc}
\hline & \multicolumn{3}{c}{ Crohn's disease } & \multicolumn{3}{c}{ Ulcerative colitis } \\
Relative & Diseased & Sample & Percentage & Diseased & Sample & Percentage \\
Mothers & 38 & 597 & 6.43 & 11 & 263 & 4.18 \\
Fathers & 22 & 591 & 3.72 & 13 & 263 & 4.94 \\
Sisters & 47 & 1006 & 4.67 & 17 & 434 & 3.92 \\
Brothers & 22 & 962 & 2.29 & 7 & 443 & 1.58 \\
Daughters & 9 & 412 & 2.18 & 2 & 220 & 0.91 \\
Sons & 5 & 427 & 1.17 & 2 & 241 & 0.83 \\
Spouses & 2 & 459 & 0.44 & 0 & 206 & 0.00 \\
\hline
\end{tabular}

\section{TABLE 2}

$\chi^{2}$ probability for paired comparisons between relative groups for diseased versus normal relatives

\begin{tabular}{lccccccc}
\hline Relative & Mothers & Fathers & Sisters & Brothers & Daughters & Sons & Spouses \\
Mothers & $\mathbf{0 . 1 9}$ & 0.68 & 0.86 & 0.03 & 0.03 & 0.02 & 0.00 \\
Fathers & 0.03 & $\mathbf{0 . 4 1}$ & 0.52 & 0.01 & 0.01 & 0.01 & 0.00 \\
Sisters & 0.13 & 0.37 & 0.52 & 0.03 & 0.03 & 0.02 & 0.00 \\
Brothers & 0.00 & 0.10 & 0.00 & 0.39 & 0.48 & 0.41 & 0.07 \\
Daughters & 0.00 & 0.17 & 0.03 & 0.91 & 0.24 & 0.93 & 0.17 \\
Sons & 0.00 & 0.01 & 0.00 & 0.16 & 0.25 & 0.68 & 0.19 \\
Spouses & 0.00 & 0.00 & 0.00 & 0.01 & 0.02 & 0.22 & 0.34 \\
\hline
\end{tabular}

Probabilities less than or equal to 0.05 are significant. Probabilities along the main diagonal are for the same relative groups compared for diseases; above the main diagonal are ulcerative colitis comparisons between relative groups: and below the main diagonal are Crohn's disease comparisons between relative groups

proximately $40 \%$ of the population, 525,000 persons, lived in or around Ed. monton, the only major city in the area. As described previously, the medical records departments of the five reaching hospitals in Edmonton and the 37 community hospitals in the seven census districts of this northern Albertan area were contacted and a search undertaken for all patients with a discharge diagnosis of Crohn's disease or ulcerative colitis (8). Also, the patient records of all 10 Edmonton gastroenterologists were reviewed in order to discover patients with Crohn's disease or ulcerative colitis who had never been hospitalized. Each of the patients identified was sent a questionnaire which enquired, among other things, into any familial occurrence of Crohn's disease or ulcerative colitis. After three mailings, 1015 of the 2430 self-administered questionnaires (41.8 $\%$ ) were returned, and these data used to calculate prevalence in the different relative groups. There were no demographic distinctions identified between those who did not respond to the questionnaire ('nonresponders') and those who did ('responders'), nor be- tween responders with a positive family history of Crohn's disease or ulcerative colitis and those without. The stated diagnosis of Crohn's disease or ulcerative colitis in the relative was not independently confirmed.

The number of diseased relatives were categorized by relationship to the index patient, location, gender and diagnosis. The numbers of diseased relatives within each relative group were divided by the total number of relatives within that group to determine the percentage of diseased relatives within the relative group. The percentage data may be converted to prevalence by multiplying by 1000 . A $\chi^{2} \quad 2 \times 2$ test was conducted between relative groups for normal versus diseased relatives to determine whether differences were significant.

\section{RESULTS}

The percentage of diseased relatives with Crohn's disease was approximately twice that in females versus males, while in ulcerative colitis the percentage of diseased relatives was only higher for sisters than for brothers (Table 1). For Crohn's disease (not in ulcerative colitis), mothers were found to have a significantly larger 'percentage diseased' than fathers, while sisters had a significantly larger 'percentage diseased' than brothers in both Crohn's disease and ulcerative colitis (Table 2). Mothers and sisters also illustrated a significantly higher 'percentage diseased' than brothers, daughters, sons and spouses for both Crohn's disease and ulcerative colitis. In Crohn's disease and ulcerative colitis, sisters were not significantly more diseased than fathers and mothers. The highest prevalence appears to be confined to the older generations; this suggests that disease onset may be delayed (Table 1). Females in the same household appear to be more susceptible to Crohn's disease.

\section{DISCUSSION}

The observed frequency of inflammatory bowel disease in relatives of patients with Crohn's disease or ulcerative colitis varies widely (Table 1). This is much higher than the frequencies expected by chance alone of observing 
Crohn's disease or ulcerative colitis in two members of the same family (Table 2) $(9,10)$. This high prevalence of Crohn's disease and ulcerative colitis in the families (and especially siblings) of patients with either disease has indicated that genetics probably plays some role in the development of these disorders $(2-7,9,11)$. It is likely that environment and lifestyle combine with genetic influences to contribute to the development of inflammatory bowel disease. The results of the present study support such a hypothesis of a genetic and environmental interaction: there was a high prevalence rate of Crohn's disease for mothers over sisters and daughters, as well as over other relations (Table 2). In the case of the sisterdaughter pair, the two individuals would share the common factor of genetics, but not necessarily the same environment to a great extent. In most cases, the daughter would not yet have been born when the sister was in the

\section{REFERENCES}

1. Langman MJS. The Epidemiology of Chroric Intestinal Disease. London: Edward Anold, 1979.

2. Weterman IT, Pena AS. Familial incidence of Crohn's disease in the Netherlands and a review of the literature. Gastroenterology 1984:86:449-52.

3. Mayberry JF, Rhodes J, Newcome RG. Familial prevalence of inflammatory bowel disease in relatives of patients with Crohn's disease. Br Med J 1980;1:84-7.

4. Singer HC, Anderson JGD, Frischer H, high risk age group for the development of Crohn's disease (16 to 20 years). Also, in some cases the daughter was either raised in a different area than the sister or in an environment that had undergone marked changes. For example, in the past 30 years in Alberta there has been a large migration of people from the lower risk rural areas to the higher risk urban area of Edmonton (8). Sisters and mothers would most probably share a similar environment and lifestyle during childhood and through the high risk years, and would therefore share both environmental and genetic factors.

Possible sampling and measurement bias in this study needs to be considered. Despite multiple mailing, the patient response rate was only $41.8 \%$. This is lower than the response rates reported in some studies (6), but the data were derived from a community source rather than from a tertiary referral centre. It is likely that sampling bias

Kirsner JB. Familial aspects of inflammatory bowel disease. Gastroenterology 1979;61:423-30.

5. Farmer RG, Michener WM, Mortimer EA. Studies of family history among patients with inflammatory bowel disease. Clin Gastroenterol 1980;9:271-8.

6. Lashner BA, Evans AA, Kirsner JB, Hanauer SB. Prevalence and incidence of inflammatory bowel disease in family members. Gastroenterology 1986;91:1396-400.

7. Sategna-Guidetti C, Bianco L, Biacco E, Marucco E. Familial incidence of was small since there were no demographic differences between responders and nonresponders, nor between responders with a family history of inflammatory bowel disease and those without. The diagnosis of Crohn's disease or ulcerative colitis in relatives was not confirmed by pathologic, radiographic, surgical or endoscopic means (as was done in the index patients), so that there may have been patients with mild Crohn's dis. ease or ulcerative colitis who were not yet diagnosed and therefore excluded from prevalence rates; this would only have resulted in an underestimation of prevalence rates in relatives.

These findings support the sugges. tion that while genetics does play an important role in the development of Crohn's disease or ulcerative colitis, it does not work alone. It would appeat that other factors in environment of lifestyle are necessary for the disease to become clinically manifest.

Crohn's disease in Italy. Dig Dis Sci 1986;31:557-8.

8. Thomson ABR, Pinchbeck BR, Kirdeikis J. Epidemiology of idiopathic inflammatory bowel disease in northern Alberta, Canada. J Clin Gastroenterol 1988;10:505-15.

9. Lewkonia RM, McConnell RB. Familial IBD - Heredity or environment? Gut 1976;17:235-43.

10. Mendeloff Al. The epidemiology of inflammatory bowel disease.

Clin Gastroenterol 1980;9:259-70.

11. Kirsner JB. Genetic aspects of IBD. Clin Gastroenterol 1973;2:557-75. 


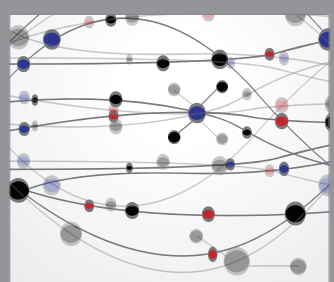

The Scientific World Journal
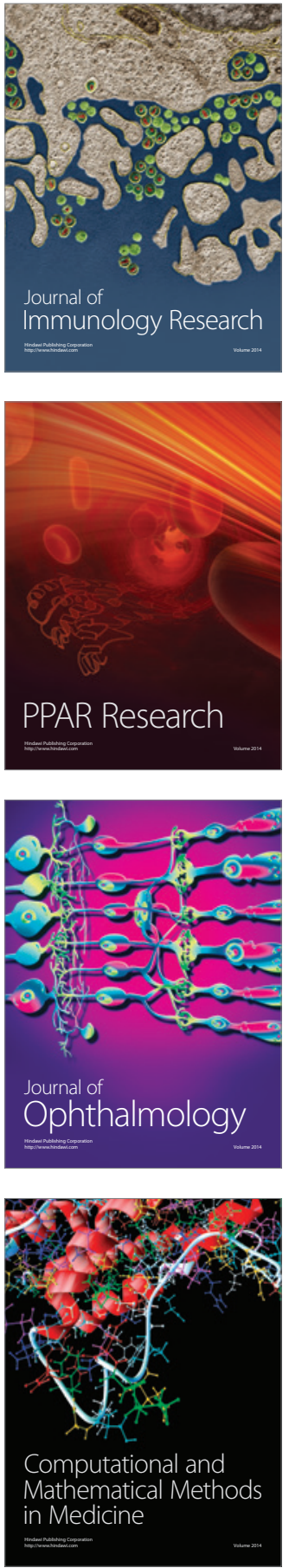

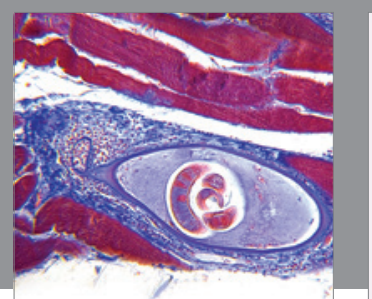

Gastroenterology Research and Practice

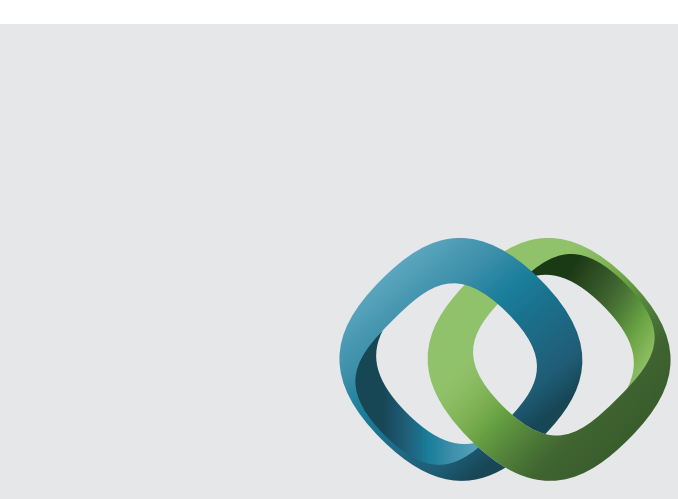

\section{Hindawi}

Submit your manuscripts at

http://www.hindawi.com
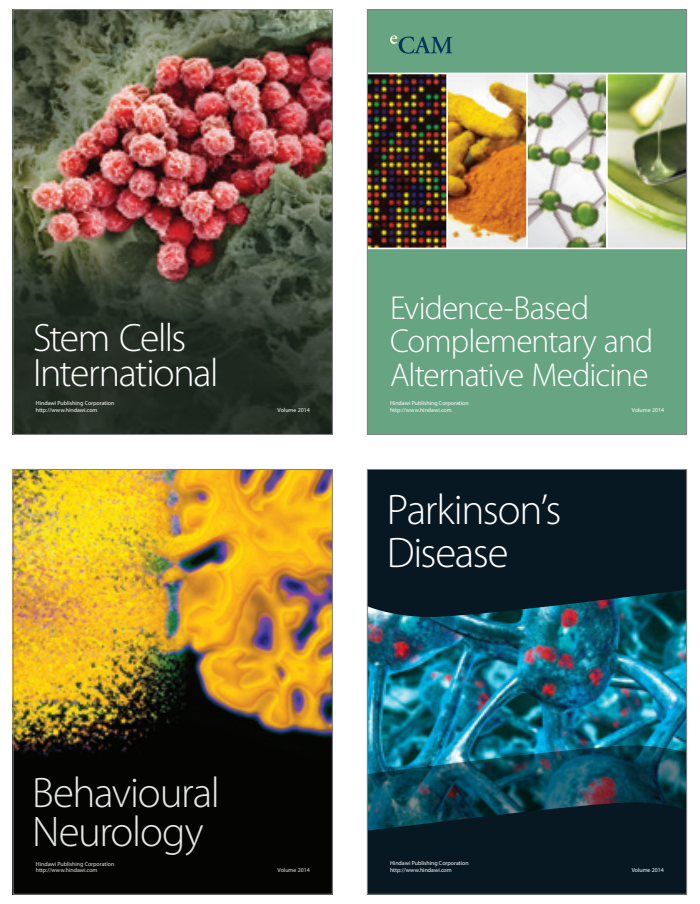
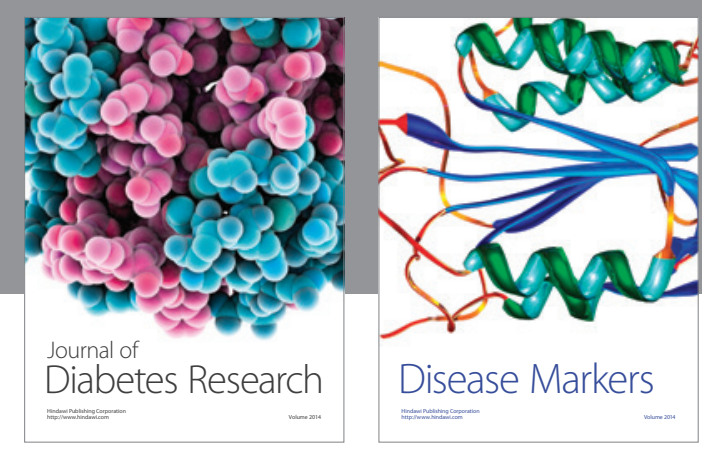

Disease Markers
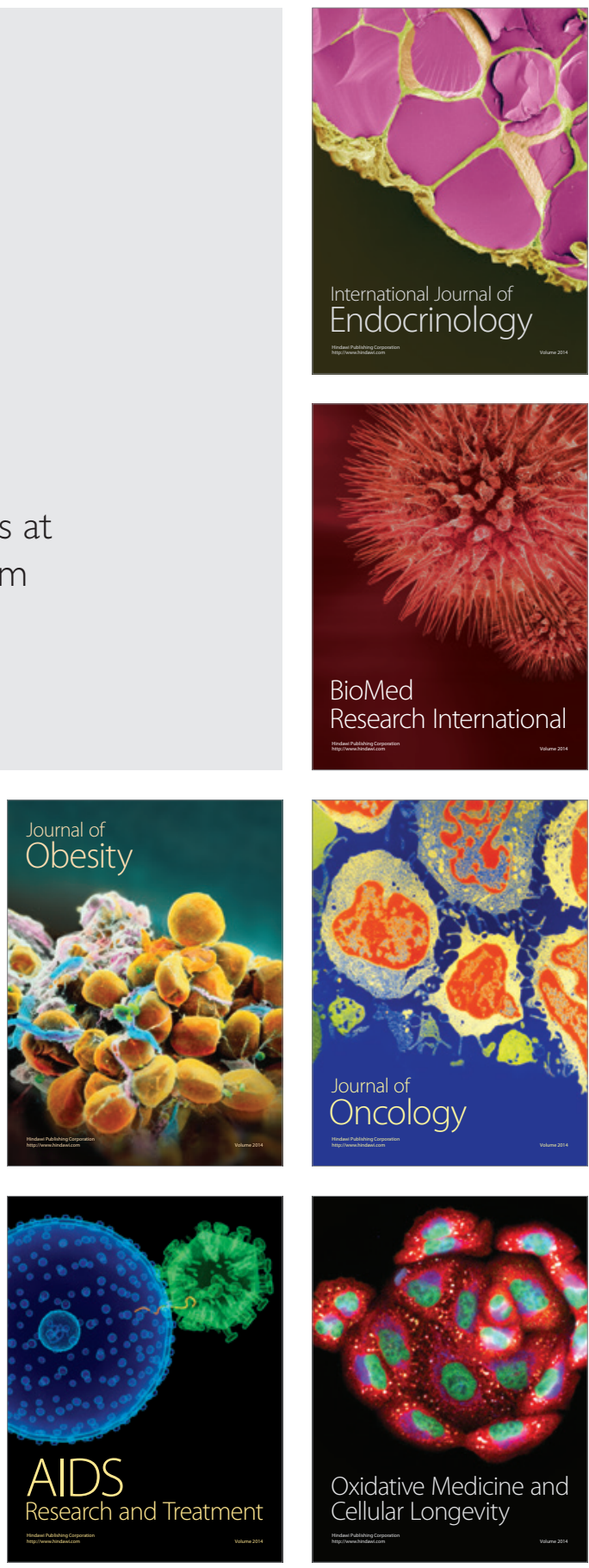